The equivalent creep-strain increment $\Delta \epsilon_{\mathrm{eq}}{ }^{\mathrm{c}}$ is computed from any flow relationship selected, which can be in a functional form in terms of factors such as stress, temperature, and fabric, and vary from element to element to reflect the conditions at that point in the unknown.

C. F. RAYMOND: Your approach seems to emphasize strain increments, stress increments, and displacement. In glaciology we have been used to thinking of ice as a fluid, at least for the purpose of practical calculations to glacier flow. We think in terms of strain-rate and velocity. Why have you chosen this approach and can it conveniently account for progressive change in structure and consequent effect on rheology caused by strain?

EMERY: The incremental initial-strain finite-element method was selected to simulate small displacement ice-flow problems as it has been developed, and successfully applied, over a number of years in geomechanics, and can handle a number of the aspects considered important such as initial states of stress and temperature, basal sliding, and functional non-linear flow relationships. Essentially, an elasto-visco-plastic approach is involved, that with the current extension to large displacements through an implicit method should be capable of simulating instability problems such as surging. One of the very positive features of the finite-element method is the capability of using a wide range of constitutive relationships if the necessary materials characterization is available. Since a marching-forward procedure is involved, the flow relationship for each element (and the stiffness) can be modified at each time step to reflect changes in stress, temperature, fabric, etc. This is incorporated into the programmes, but it must be emphasized again, that such modifications depend on being able to characterize the ice.

\title{
REFERENCE
} Greenbaum, G. A. Unpublished. Creep analysis of axisymmetric bodies. [Ph.D. thesis, University of
California-Los Angeles, r 966 .]

\section{ICE-SHEET SURFAGE ELEVATION AND CHANGES OBSERVABLE BY SATELLITE RADAR ALTIMETRY}

\author{
By H. Jay Zwally, \\ (NASA-Goddard Space Flight Center, Greenbelt, Maryland 20771, U.S.A.) \\ R. L. BROOKS,
}

(EG \& G Washington Analytical Services Center, Pocomoke City, Maryland 21851, U.S.A.)

H. Ray Stanley,

(NASA-Wallops Flight Center, Wallops Island, Virginia 23337, U.S.A.)

and $\mathrm{W}$. J. CampbelL

(U.S. Geological Survey, Tacoma, Washington 98416 , U.S.A.)

Abstract. A major question in ice-sheet dynamics is the state of balance between the net mass input and ice flow. Since an imbalance produces a change in surface elevation, the state of balance can be studied by monitoring the elevation, and this has been accomplished by surface-leveling techniques in a few locations. Due to the requirement for accurate and repetitive measurements over large areas, it is not practical to determine the status of balance of an entire ice sheet or even a major drainage basin by conventional techniques. Now, recent 
results from satellite-borne radar altimeter measurements over the Greenland ice sheet demonstrate the feasibility of accurately measuring and monitoring the topography of large ice masses. The application of this new technique offers the possibility of making a meaningful mass-balance determination and for detecting actual or potential ice-sheet surges.

The initial analysis of the GEOS-3 satellite radar-altimeter data showed an accuracy of about two meters (Brooks and others, 1978). The major residual uncertainty was due to inaccuracies in the determination of the satellite orbital position. This uncertainty has been reduced by minimization of differences in the elevations observed at intersections of the satellite-nadir tracks. By using only intersections over the adjacent ocean, a solution is obtained that is independent of any actual elevation changes during the time intervals between the intersection of the tracks. The improved accuracy thus obtained has made it possible to analyze the data for elevation changes that might have occurred during the three-year period of data collection by GEOS-3.

A topographic map having a contour interval of $10 \mathrm{~m}$ has been constructed for most of the Greenland ice sheet south of lat. $65^{\circ} \mathrm{N}$. The present results have not been corrected for the effect of surface slope (Robin, I 966; Brooks and others, I978). Therefore, the true surface may lie below the indicated surface by as much as $\Delta h=h \alpha^{2} / 2$ (e.g. $\Delta h=4.7 \mathrm{~m}$ for surface slope $\alpha=\mathrm{I} / 300$ and satellite altitude $h=844 \mathrm{~km}$ ). Since the altimeter measurement is the distance to the mean surface within the altimeter footprint (footprint diameter is $3.6 \mathrm{~km}$ ), slopes or undulations having horizontal extent small compared to the footprint have little effect. Correction for the effect of slopes having a larger horizontal scale can be made provided the data set is sufficiently dense.

Surface undulations or waves of various amplitudes and wavelengths are observed on the ice sheet. Over much of the surface, waves on the order of $10 \mathrm{~m}$ amplitude and $10 \mathrm{~km}$ in wavelength appear to be predominant. These observed wavelengths are about six times the ice thickness, which is consistent with Budd's (1969) conclusion that surface undulations having wavelengths 2 to ro times the ice thickness should be predominant with the shorter and longer wavelengths generated by bedrock irregularities being more severely damped within the ice. The surface topography is also observed to be more irregular near the southernmos portion of the ice sheet due to the more irregular bedrock topography.

\section{REFERENCES}

Brooks, R. L., and others. I978. Ice sheet topography by satellite altimetry, [by] R. L. Brooks, W. J. Campbell, R. O. Ramseier, H. R. Stanley, and H. J. Zwally. Nature, Vol. 274, No. 5671, p. 539-43.

Budd, W. F. I 969 . The dynamics of ice masses. ANARE Scientific Reports. Ser. A(IV). Glaciology. Publication No. 108.

Robin, G. de Q. 1966. Mapping the Antarctic ice sheet by satellite altimetry. Canadian Fournal of Earth Sciences, Vol. 3, No. 6, p. 893-901.

\section{DISCUSSION}

T. J. Hughes: The altitude changes you might detect over a decade or so by this method can reflect either mass-balance changes or snow-density changes related to climatic warming or cooling over the decade. Can other satellite remote-sensing methods allow you to distinguish between these possibilities.

H. J. ZwAlly: Not directly, but microwave techniques can provide information on firn grain size, accumulation, and temperature which may be related to firn compaction. However, understanding of the magnitude of possible firn compaction effects due to climatic temperature changes, or accumulation changes, requires additional field and theoretical studies of firn compaction processes. 
C. R. Bentley: How many satellite crossing lines are there in the large-scale (ro $\mathrm{m}$ contour line) map of surface elevations around the dome area?

ZWALLY: This preliminary map includes only about 12 lines. Therefore, some of the smaller features are probably artificial.

\title{
REGONSTRUGTION AND DISINTEGRATION OF ICE SHEETS FOR THE CLIMAP I 8000 AND I 25000 YEARS B.P. EXPERIMENTS: THEORY
}

\author{
By T. J. Hughes \\ (Department of Geological Sciences and Institute for Quaternary Studies, University of Maine, \\ Orono, Maine 04473, U.S.A.)
}

Abstract. Size, shape, and surface albedo of former ice sheets are needed in order to model atmospheric circulation for the CLIMAP I 8 ooo years B.P. experiment. Both the size and shape of an ice sheet depend on the hardness of ice and its coupling to bedrock. Ice hardness is controlled by ice temperature and fabric, which are not adequately described by any ice flow law. Ice-bed coupling is controlled by bed roughness and basal melt water, which are not adequately described by any ice sliding law. With these inadequacies in mind, we assumed equilibrium ice-sheet conditions 18 ooo years ago and combined the standard steady-state flow and sliding laws of ice with the equation of mass balance to obtain separate basal shear-stress variations along ice-sheet flow lines for a frozen bed when the flow law dominates and for a melted bed when the sliding law dominates. Theoretical basal shearstress variations were then derived for freezing and melting beds on the assumption that separate melted areas of the bed had water films of constant thickness which expanded and merged for a melting bed but contracted and separated for a freezing bed. Theoretical basal shear-stress variations were also derived for ice streams along marine ice-sheet margins and ice lobes along terrestrial ice-sheet margins on the assumption that the entire area of their bed was wet so that further melting increased the water-layer thickness, which would then be decreased by freezing. Melting was assumed to continue to the grounding line of an ice stream and the minimum-slope surface inflection line of an ice lobe, where freezing began and continued to the ice-lobe terminus. Ice-bed uncoupling is complete at an ice-stream grounding line and maximized at an ice-lobe minimum-slope inflection line, so ice velocity and consequent generation of frictional heat were assumed to reach maxima across these lines. Theoretical basal shear-stress variations were derived for the zone of converging flow at the heads of ice streams and ice lobes, and from domes to saddles along the ice divide for both frozen and melted beds.

Criteria based on the glacial geology and topography were developed to assess which areas underneath ice sheets 18 ooo years ago were covered by freezing, frozen, melting, or melted beds, ice streams or lobes, and ice domes or saddles. Our ice sheets were then reconstructed using a finite-difference model that requires as input the ice thickness near the ice-sheet margin, the basal topography under ice-sheet surface flow lines, flow-line lengths, and basal shearstress variations along flow lines. Initial ice thicknesses could be somewhat arbitrary because they only affected the flow-line surface profile close to the ice-sheet margin. Present bed 